\title{
Can healthy checkout counters in supermarkets promote healthier food choices? Two real-life experiments in supermarkets in a disadvantaged urban area in the Netherlands
}

\section{Marlijn Huitink ( $\nabla$ m.huitink@vu.nl )}

Vrije Universiteit Amsterdam Faculteit der Aard- en Levenswetenschappen https://orcid.org/0000-00025303-9668

\section{Maartje P. Poelman}

Wageningen Universiteit

Jacob C. Seidell

Vrije Universiteit Amsterdam

Lothar D. J. Kuijper

Vrije Universiteit Amsterdam

\section{Trynke Hoekstra}

Vrije Universiteit Amsterdam

\section{S. Coosje Dijkstra}

Vrije Universiteit Amsterdam

\section{Research}

Keywords: supermarkets, checkout counter, purchase behavior, food purchases, snacks, impulsive behavior, food environment

Posted Date: May 18th, 2020

DOI: https://doi.org/10.21203/rs.3.rs-29147/v1

License: (c) (i) This work is licensed under a Creative Commons Attribution 4.0 International License. Read Full License 


\section{Abstract \\ Background}

Most foods displayed at supermarket checkouts are unhealthy and do not support healthy purchases. This study investigates the sales effects of introducing healthier alternatives at supermarket checkouts.

\section{Methods}

We performed two real-life quasi-experimental studies in supermarkets located in a disadvantaged urban area in the Netherlands. In Study 1, we examined the impact of substituting healthier options for all the unhealthy snacks at checkouts ( $n=1$ supermarket). In Study 2, we investigated the impact of placing healthier snacks at checkouts (placement intervention), as well as the impact of offering a discount on healthier checkout snacks (placement + price intervention), while continuing to display unhealthy snacks for sale ( $n=2$ supermarkets). Supermarket sales data were used to measure purchases.

\section{Results}

In Study 1, median weekly sales/1000 customers of checkout snacks were 2.3 times lower (SE: 1.1, 95\% $\mathrm{Cl}$ : 1.9-2.7) during the intervention period - when healthier options were substituted for the entire unhealthy snack assortment - (median: 10, IQR: 2.8), as compared to the control period (median: 24, IQR: 2.8). In Study 2, median daily sales/1000 customers of healthier snacks were 2.1 times higher (SE: 1.3, 95\% Cl: 1.3-3.3) during the placement-intervention period (median: 7.8, IQR: 4.6), as compared to the control period (median: 4.2, IQR: 4.6). Similarly, median daily sales/1000 customers of healthier snacks were 2.7 times higher (SE: 1.2, 95\% Cl: $2.0-3.6$ ) during the placement + price-intervention period (median: 5.8, IQR: 2.2), as compared to the control period (median: 2.2, IQR: 4.7). There was no difference between the effect of the placement intervention and that of the placement + price intervention (ratio: 1.1, SE: 1.3, 95\% Cl: 1.7-1.9). Neither did we observe a decline in purchases of unhealthy snacks (ratio: 1.3, SE: 1.1, $95 \%$ Cl: $1.1-1.5)$.

\section{Conclusions}

This study showed that if we want to promote healthier food purchases at supermarket checkouts the substitution of the unhealthy snacks with healthier alternatives is an effective intervention, which is not the case if the unhealthy snacks remain in place at the checkouts, even with discounts on the healthier snacks. Future research should assess the feasibility and willingness of eliminating unhealthy checkout snacks in supermarkets.

\section{Background}


The consumption of energy-dense, nutrition-poor and ultra-processed foods and drinks has increased in many countries in recent decades $(1,2)$. The consumption of these foods and drinks has contributed to an increase in overweight, obesity and other diet-related chronic diseases $(3,4)$. It is well established that the food environment, within which people purchase and consume foods and drinks, is one of the most dominant factors influencing food choices and intake (5). Supermarkets are an important setting for food purchases, as they are the primary source of food for many people in affluent countries, like the Netherlands. For this reason, supermarkets have a major influence on food choices (6-11). Individual food choices in supermarkets are influenced by various in-store marketing techniques focussing on the placement, price and promotion of products (12). These marketing techniques increase the likelihood that consumers will make impulse purchases (13). They are predominantly used for the promotion of unhealthy foods and drinks (14-17), however, despite evidence that these strategies can also be used to promote healthy food choices in supermarkets (18-20). Checkout counters are an unavoidable point in supermarkets, and they are characterized by high levels of impulsive food purchases $(21,22)$. Most of the products that are sold at these counters, however, are unhealthy (23). Various intervention studies have been conducted to evaluate attempts to optimize the healthiness of the checkout-counter assortment. Previous studies have indicated that the substitution of healthier alternatives for some unhealthy snacks is a promising strategy for promoting healthier food purchases at supermarket checkouts (24-26). Nevertheless, the effect of substituting healthy alternatives for the total assortment of unhealthy snacks at all of the checkout counters in supermarkets has yet to be investigated.

As indicated by multiple studies (27-31), price discounts on healthy foods are another effective strategy for promoting healthy food purchases in supermarkets since price is one of the most important factors influencing food purchases, especially amongst people from groups of lower socioeconomic position (SEP) (32). It is nevertheless unknown whether additional price discounts on healthier checkout snacks could steer consumers towards making healthier food purchases at supermarket checkout counters. To the best of our knowledge, most interventions involving the introduction of healthier snacks at checkouts have been conducted in supermarkets in neighbourhoods of middle or higher SEP. In our view, however, it would seem especially important to promote healthier food choices amongst people from lower SEP groups, as they tend to have less favourable diets relative to those from higher SEP groups $(33,34)$.

The research reported in this article consisted of two studies investigating the effects of the introduction of healthier snacks at checkout counters on sales in supermarkets in a disadvantaged urban area in the Netherlands. In the first study, we examined the impact of substituting healthier snack options for unhealthy snacks at checkouts. In the second study, we investigated the impact of placing healthier snacks at checkouts (placement intervention), as well as the impact of offering a price discount on these healthier snack options (placement + price intervention) while allowing the unhealthy snacks to remain for sale at checkouts during both interventions.

\section{Methods}




\section{Study 1 - Substituting healthier options for unhealthy snacks at checkout counters}

In the first study, we examined the impact of substituting healthier snack options for unhealthy snacks at checkout counters.

\section{Design and setting}

The first study was conducted in one supermarket located in a disadvantaged area in the South-eastern part of Amsterdam, the Netherlands between September and December 2015, using a quasi-experimental real-life design with a control and intervention period. During the eight-week control period, the regular unhealthy snacks were offered at the checkout counters as usual. This was followed by an eight-week intervention period, during which healthier options were substituted for the unhealthy snacks. The Medical Ethics Committee of Vrije Universiteit Amsterdam confirmed that this study was not subject to the Medical Research Involving Human Subjects Act (WMO), due to the nature of the measurements (anonymous sales data). The request for approval was therefore waived. The study was conducted in a supermarket located in a disadvantaged area in the South-eastern part of Amsterdam, the Netherlands. Neighbourhood disadvantage was established according to the Valuation of Immovable Property Act (VIPA) (35). This Act specifies how municipalities are to assess the value of homes and businesses within specific neighbourhoods, which is strongly associated with the average SEP of the people living in those neighbourhoods. A supermarket that was situated in a neighbourhood with a very low VIPA was selected for this study.

\section{Healthy Checkout Counter (HCC) Intervention}

The intervention consisted of removing the entire assortment of unhealthy snacks displayed beside the conveyor belts of all of the checkout counters and replacing them with healthier single-pack snacks (e.g. nut bars, cereal bars). In addition, displays of single-pack healthier snacks and ready-to-eat (e.g. fresh and pre-packed) fruit and vegetables were placed at the ends of the conveyor belts at $25 \%$ of the checkouts. The healthier snacks, which were selected by the supermarket chain, consisted of well-selling ready-to-use products (e.g. pieces of fruit, pre-packed vegetables, bottled water) that had already been sold before the HCC intervention, as well as newly introduced healthier snack items (e.g. nut bars, cereal bars, smoothies, sliced and pre-packed fruit and vegetables), specifically developed for the HCC intervention by the supermarket chain's food suppliers. These healthier snacks were lower in added sugar or saturated fat than were the regular unhealthy snacks that were offered for sale at the checkouts. In all, 38 unhealthy snacks were offered for sale exclusively at the checkouts during the control period, and they were replaced with 28 healthier snacks during the intervention period.

\section{Outcome measures}

The main outcome measures were weekly sales of snacks purchased/per 1000 customers at the checkout counters (for unhealthy snacks during the control period and for healthier snacks during the intervention period). Given that we were interested only in the impact of the intervention on snacks that 
were sold exclusively at the checkout counters, products that were also displayed in other locations in the supermarket were excluded $(n=7)$.

\section{Statistical analyses}

Descriptive statistics were used to examine the sales of the snacks sold at the checkout counters during the control period (unhealthy snacks) and during the intervention period (healthier snacks). Because the sales data were not normally distributed, they are presented as medians with IQR. Sales volumes (i.e. the number of items sold) differ considerably across the different types of snacks used in this study. It is thus not possible to make any meaningful comparison across these snacks. To examine the extent of the intervention's effect on sales, we standardized the sales data for the snacks by taking the logarithms of their sales. The data were analysed using the natural logarithms to calculate the proportional change in sales between the intervention and control period. We subsequently conducted an independent-sample ttest to investigate the proportional change in checkout sales between the intervention and control period. Log-transformed results were back-converted to ratios for presentation and interpretation. The outcome represents the ratio between the geometric means of the intervention period, as compared to the control period. Statistical analyses were performed using the statistical software package IBM SPSS Statistics for Windows, version 25.0.

\section{Results}

During the control period, the median weekly sales of unhealthy snacks amounted to 24 items (IQR: 2.8) per 1000 customers. During the intervention period, the median weekly sales of healthier snacks amounted to 10 (IQR: 4.5) items per 1000 customers (Figure 1). Sales of checkout snacks (unhealthy snacks in the control period vs. healthier snacks in the intervention period) were 2.3 (SE: 1.1, 95\% Cl: $1.9-$ $2.7 ; t(8)=11.0)$ times lower during the intervention period, as compared to the control period.

[insert Figure 1]

\section{Conclusions}

The results of this study indicate that removing the entire assortment of unhealthy snacks from supermarket checkouts resulted in an overall decrease in the sales of checkout snacks. The reduction in the sales of unhealthy snacks was thus not compensated by purchases of healthier snacks.

\section{Study 2 - Placement of healthier snacks at checkouts, combined with a price discount}

In the second study, we investigated the impact of placing healthier snacks at checkouts as well as the impact of offering a price discount for the healthier checkout snacks, while keeping the unhealthy 


\section{Design and setting}

The second study was conducted in two supermarkets located in a disadvantaged area in the Southeastern part of Amsterdam, the Netherlands between April and June 2017, using a quasi-experimental real-life design with a control period and an intervention period. Neighbourhood disadvantage was established in the same manner described in the Methods section for the first study. During a two-week control period, the regular unhealthy snacks were offered at the checkout counters as usual. This was followed by a six-week intervention period, during which additional healthier snacks were offered at the checkouts, either with or without a price discount of approximately $15 \%$. The unhealthy snacks remained for sale at the checkouts throughout the entire intervention period. The Medical Ethics Committee of Vrije Universiteit Amsterdam confirmed that this study did not require formal approval by the Medical Research Involving Human Subjects Act (WMO), due to the nature of the measurements (anonymous sales data). The request for approval was therefore waived.

[insert Table 1]

\section{Healthy Checkout Counter (HCC) Intervention}

The intervention consisted of placing three displays at the ends of the conveyor belts in front of the checkout counters, offering single packages of healthier snacks that had already been sold in the two supermarkets before the intervention. There were two types of interventions: 1) a placement intervention, in which the healthier snacks were offered at the checkout counter and 2) the placement + price intervention, in which the healthier checkout snacks were offered at an additional price discount. The placement intervention and the placement + price intervention were alternated between the two supermarkets during the six-week intervention period (see Table 1). During the six-week intervention period, the assortment of healthier snacks was changed every two weeks, resulting in three consecutive two-week periods offering different types of healthier snacks including 1 ) vegetable snacks (tomatoes and cucumbers), 2) unsalted nuts (five different types) and 3) vegetable snacks (tomatoes and bell peppers) (Figure 3). We conducted separate comparisons of the sales of the three types of healthier snacks during each two-week period to the sales during the two-week control period for the placement intervention and the placement + price interventions. The healthier snacks were selected by the research team and met the guidelines of the Dutch Nutrition Centre (36). The unhealthy snacks remained in their usual place at the checkout counters.

[insert Figure 3]

\section{Outcome measures}


The main outcome measures were daily sales data for both the unhealthy snacks and the healthier snacks purchased/per 1000 customers. The sales data for the unhealthy snacks refer only to products that were offered exclusively at the checkout counters. The sales data for the healthier snacks refer to products that were placed at the checkout counters, as well as in another place in the supermarket (e.g. in the vegetable department). This was because the supermarket chain was not able to separate the sales data for products that were placed in two (or more) locations in the supermarket. In all, the study addressed 94 unhealthy snacks that were sold exclusively at the checkouts and 9 healthier snacks.

\section{Compliance}

During the intervention period, the researcher assessed the extent to which the intervention was being implemented as intended in the two supermarkets throughout the six-week period by making unannounced weekly visits to the intervention supermarkets and by contacting the managers of the supermarkets by telephone. During each visit, the researcher recorded compliance with the strategies (placement vs. placement + price) and documented the implementation of the intervention with photographs. This resulted in a list of days on which the intervention had been executed correctly and those on which it had not been executed correctly.

\section{Statistical analyses}

Descriptive statistics were used to examine the sales of unhealthy and healthier snacks during the control and intervention periods. Because the sales data were not normally distributed, they are presented as medians with IQR. For the reasons described in the first study, we examined the extent of the effect of the intervention on sales by standardizing the sales data for the snacks included in this study by using their logarithms. The data were analysed using the natural logarithms in order to calculate the proportional changes in sales between the intervention and control periods. Because the sales data included zero values, we added a constant value to the data prior to applying the log transformation (37). We subsequently conducted independent-sample t-tests to investigate the proportional change in sales between the intervention and control periods for the sales of (1) healthier snacks in the placement intervention, (2) healthier snacks in the placement + price intervention and (3) unhealthy snacks. An additional independent-sample t-test was conducted to investigate the proportional change between the intervention and control periods in the sales of the healthier snacks between the placement + price condition and the placement condition. Log-transformed results were back-converted to ratios for presentation and interpretation. The outcome represents the ratio between the geometric means of the intervention period as compared to the control period. The same statistical procedure was applied when analysing the data according to the per-protocol approach, in order to investigate the effect of the intervention excluding sales data for the healthier snacks from days on which the intervention was not executed correctly. Statistical analyses were performed using the statistical software package IBM SPSS Statistics for Windows, version 25.0. 


\section{Results}

The median sales per 1000 customers per day of the healthier snacks in the placement intervention increased from 4.2 (IQR: 4.6) items in the control period to 7.8 (IQR: 4.6) items in the intervention period (Fig. 3). Sales of the healthier snacks during the placement intervention were 2.1 (SE: 1.3, 95\% Cl: 1.3$3.3 ; \mathrm{t}(53)=3.2, \mathrm{p}<0.001)$ times higher, as compared to the control period (Table 2). In line with these results, sales of the healthier snacks during the placement + price intervention increased from 2.2 (IQR: 4.7) items in the control period to 5.8 (IQR: 2.2) items in the intervention period. Sales of the healthier snacks during the placement + price intervention were 2.7 (SE: 1.2, 95\% Cl: 2.0-3.6; 110) =6.9, p < 0.001) times higher, as compared to the control period. No statistically significant difference in effect was found between the placement and the placement + price interventions with regard to the increase in sales of the healthier snacks between the intervention and control periods (ratio: 1.1, SE: 1.3, 95\% Cl: $0.7-1.9 ; \mathrm{t}(29)=$ $0.2, p=0.8$ ). Furthermore, the median sales per 1000 customers per day of the unhealthy snacks increased from 15.4 (IQR: 1.8) items in the control period to 18.1 (IQR: 1.4) items in the intervention period (including both placement and placement + price intervention). Sales of the unhealthy snacks were 1.3 (SE: 1.1) times higher in the intervention period (including both placement and placement + price), as compared to the control period $(95 \% \mathrm{Cl}: 1.1-1.5 ; \mathrm{t}(40)=3.8, \mathrm{p}<0.001)$. The per-protocol analyses revealed similar results (data not shown). 
Table 2

Effect of the healthy checkout counter (HCC) intervention on the sales of unhealthy snacks at checkout counters and the sales of the healthier snacks (placement, placement + price intervention separately) between the intervention period and the control period.

\begin{tabular}{|c|c|c|}
\hline & $\begin{array}{l}\text { Ratio (SE) } \\
\% 95 \mathrm{Cl}^{1}\end{array}$ & t-value \\
\hline \multirow[t]{2}{*}{ Placement of healthier snacks } & $2.1(1.3)^{\star}$ & 3.2 \\
\hline & $1.3-3.3$ & \\
\hline \multirow[t]{2}{*}{ Placement + price of healthier snacks } & $2.7(1.2)^{\star}$ & 6.9 \\
\hline & $2.0-3.6$ & \\
\hline \multirow[t]{2}{*}{ Placement + price intervention vs. placement intervention } & $1.1(1.3)$ & 0.2 \\
\hline & $0.7-1.9$ & \\
\hline \multirow[t]{2}{*}{ Unhealthy snacks at checkout counters } & $1.3(1.1)^{\star}$ & 3.8 \\
\hline & $1.1-1.5$ & \\
\hline \multicolumn{3}{|c|}{$\begin{array}{l}1 \text { Independent-sample t-tests performed on log-transformed data; ratio is the exponent of the log- } \\
\text { transformed outcome }\end{array}$} \\
\hline \multicolumn{3}{|l|}{$* P<0.05$} \\
\hline \multicolumn{3}{|l|}{$\mathrm{SE}=$ standard error } \\
\hline \multicolumn{3}{|l|}{$\mathrm{Cl}=$ confidence interval } \\
\hline
\end{tabular}

[insert Fig. 3]

[insert Table 2]

\section{Conclusions}

This study showed that if we want to promote healthier food purchases at checkouts in supermarkets the substitution of the entire unhealthy snack assortment with healthier alternatives at the checkouts is an effective intervention, which is not the case if the unhealthy snacks remain in place, even with a discount on the healthier snacks. Future studies should further assess the feasibility and willingness of removing snacks from checkouts in supermarkets and finding substitute (non-food) products to protect both profit margins and consumer health. Moreover, a healthy checkout counter should be assessed as part of a multi-component intervention in supermarkets to promote healthier food purchases during the entire supermarket shopping experience.

\section{General Discussion (Study 1 And Study 2)}


This study showed that substituting the entire unhealthy snack assortment with healthier alternatives at supermarket checkouts is the most effective strategy for improving snack purchases at supermarket checkouts, which is not the case when providing healthier snacks in addition to the usual unhealthy snacks at the checkouts in supermarkets, even with a discount on the healthier snacks. In these two studies, we attempted to create a healthier checkout environment in supermarkets by introducing healthier snacks at the checkout counters. The modest intervention effects and the limited purchase of healthier checkout snacks in both of the studies are similar to those obtained in previous studies $(25,38-$ 40). For example, an experimental study conducted in supermarkets in Denmark showed that replacing unhealthy snacks with healthier options (e.g. fruit and vegetables) at a single checkout counter merely resulted in a modest effect on the sales of carrots, but not on the sales of any of the other healthier snacks that were provided at the checkout (25). Another real-life experiment conducted in the Netherlands demonstrated that placing healthier snacks at two checkout displays in a railway-station kiosk while repositioning the unhealthy snacks and displaying them elsewhere in the kiosk increased the proportion of the healthier snacks sold at the checkout displays from 4-6\% per day. This translates into a slight daily increase of approximately 10 healthier snacks per day (39). Previous studies have reported results similar to those obtained in Study 2, in which purchases of unhealthy snacks were not replaced by purchases of healthier options (41-43). It is important to note that, in Study 2, fewer healthier snacks were available relative to the large assortment of unhealthy snacks at the checkouts. Moreover, the displays containing the healthier snacks were placed in front of the checkout counters, while the unhealthy snacks were located at the conveyor belts. As a result, customers had limited exposure to the healthier snacks and were exposed to the unhealthy snacks more frequently and for a longer time and exposure of the healthier snacks was maybe too low to cause an effect. Taken together, the results of this and other studies suggest that placing healthier products at supermarket checkouts, while leaving the unhealthy snacks in place, is not sufficient to steer consumers towards making healthier food choices in supermarkets.

The results of this study provide further support for the idea that removing unhealthy snacks from supermarket checkout counters is likely to decrease some unhealthy food purchases. As demonstrated in a previous study, checkout food policies aimed at limiting unhealthy food products at supermarket checkout counters, which were introduced voluntarily by six major supermarket chains in the United Kingdom, resulted in a reduction of purchases of common unhealthy checkout snacks. Moreover, this reduction was sustained over a year (23). Despite the reduction in the overall sales of checkout snacks observed in both our Study 1 and this previous study, limiting the assortment of unhealthy snacks offered at checkout counters could potentially help supermarkets create an environment that supports healthier food choices, and it might be an important method that could have an impact on population health. It is nevertheless important to consider the financial consequences of such interventions for supermarkets. A reduction in the sales of checkout snacks might pose an economic risk that supermarkets are not willing to accept. Re-arranging the checkout environment to promote healthier food choices might require a different business model, and this should be considered when implementing such interventions in supermarkets. Encouraging supermarkets to find substitute checkout products (e.g. batteries or other non- 
food products) that would protect profit margins without having a potentially adverse impact on the health of consumers could be worth considering. Our studies are subject to a number of strengths and limitations. A major strength was that we conducted real-life experiments at checkout counters in supermarkets. In doing so, we intervened at a key point in the food-purchasing behaviour of many people. In addition, we used sales data from supermarkets to measure food purchases, thus resulting in objective data that have been shown to provide a reasonably accurate measure of overall dietary quality $(44,45)$. It is nevertheless important to note that food purchases do not necessarily reflect food consumption, which should be taken into account when considering the implications of our results. Furthermore, to our knowledge, ours is the first study to examine the impact of replacing the entire assortment of unhealthy snacks from all of the checkout counters in a supermarket with healthier alternatives (Study 1 ). It is also one of the first to combine a placement strategy with an additional discount at the checkout in order to promote healthy food purchases (Study 2). Our study therefore adds relevant information to the growing body of literature on healthy checkout counter (HCC) interventions in supermarkets. Despite these contributions, our study is subject to several limitations. With respect to the first study, the healthier snacks were developed and selected by the supermarket chain, and they did not all meet the Guidelines of the Dutch Nutrition Centre (36). They were however healthier options than those that were regularly offered for sale. With respect to the second study, the healthier checkout snacks were also offered at a second location in the supermarket, and we were not able to isolate the checkout sales of these products from their sales in other locations. Although an overall increase in the sales of healthier snacks is a desirable outcome from a public-health perspective, we cannot estimate the exclusive impact of a checkout-counter intervention, as we did not measure the location in the supermarket from which the products were taken. Another limitation of our two studies has to do with internal validity, due to the challenges of conducting experiments in supermarkets. Although they did examine food purchases in a real-life setting, our studies were not conducted in a controlled setting, and the results are limited to three supermarkets within a short intervention period. We were therefore unable to consider seasonal variations and secular trends in food purchases, nor could we control for such time-dependent factors. Future studies should include a larger sample of supermarkets and investigate the effects of such interventions over a period of at least one year. Because we did not have access to individual-level purchase data, we were not able to investigate the effects of the interventions at the household or individual level. For example, the results of our studies cannot be used to assess whether customers were triggered to select healthier options over unhealthy snacks or to purchase additional healthier snacks at the checkout counter. To generate further insight into this matter, future studies should examine changes in individual food purchases. A final limitation of our research is that the results cannot be generalized to the population as a whole, as the supermarkets included in our studies were located in a disadvantaged urban area.

The introduction of healthier snacks at supermarket checkout counters is practically feasible, requires little effort to implement and could be one factor contributing to the promotion of healthier food choices in supermarkets. Nevertheless, a healthier checkout environment alone might be too limited to have any substantial impact on overall food purchases in supermarkets, especially given the fact that the majority 
of the food products available in supermarkets are unhealthy $(16,46,47)$. In addition to the checkout environment, other places within the supermarket (e.g. the ends of aisles, shelves at eye level and island bins) are considered unhealthy and are designed to increase impulsive purchases of unhealthy food (15, $16,21,48)$. Future studies should therefore assess a healthy checkout counter as part of a multicomponent intervention to promote healthier food purchases during the entire supermarket shopping experience. Previous reviews have indicated that supermarkets should combine effective health interventions that are implemented simultaneously in order to create an environment that supports healthy food choices $(18,19)$.

\section{Declarations}

\section{Ethics approval and consent to participate}

The Medical Ethics Committee of Vrije Universiteit Amsterdam confirmed that this study is not subject to the Medical Research Involving Human Subjects Act (WMO), due to the nature of the measurements (sales data). The request for approval was therefore waived.

\section{Consent for publication}

Not applicable.

\section{Availability of data and materials}

The datasets generated and analysed during the current study are available from the corresponding author on reasonable request.

\section{Competing interests}

The authors declare that they have no financial relationships relevant to this article. The supermarket chain collaborated in the organization of the study, but did not have any role in the analyses of this study. Official representatives of the supermarket chain signed a contract and agreed that the results of this research would be published regardless of their outcomes.

\section{Funding}

The research reported in this article was funded by the Municipality of Amsterdam and Vrije Universiteit Amsterdam. 


\section{Author contribution}

$\mathrm{MH}$ contributed to the design of the study, collected the data, carried out the data analysis and wrote the manuscript. LK and TH carried out the data analysis. CD, MP and JS developed the design of the study, interpreted the results and reviewed and critiqued the manuscript. All authors played a role in data interpretation and writing of the manuscript and approved the final version of the manuscript.

\section{Acknowledgements}

We would like to acknowledge the support team of the supermarket chain (Albert Heijn), who provided the sales data. We would also like to thank the supermarket manager and employees for their participation in this study.

\section{References}

1. Imamura F, Micha R, Khatibzadeh S, Fahimi S, Shi P, Powles J, et al. Dietary quality among men and women in 187 countries in 1990 and 2010: a systematic assessment. The Lancet Global Health. 2015;3(3):e132-e42.

2. Geurts M, van Bakel A, van Rossum C, de Boer E, Ocke M. Food consumption in the Netherlands and its determinants: Background report to'What is on our plate? Safe, healthy and sustainable diets in the Netherlands.'. 2017.

3. Guh DP, Zhang W, Bansback N, Amarsi Z, Birmingham CL, Anis AH. The incidence of co-morbidities related to obesity and overweight: a systematic review and meta-analysis. BMC Public Health. 2009;9(1):88.

4. Sotos-Prieto M, Bhupathiraju SN, Mattei J, Fung TT, Li Y, Pan A, et al. Association of Changes in Diet Quality with Total and Cause-Specific Mortality. N Engl J Med. 2017;377(2):143-53.

5. Swinburn BA, Sacks G, Hall KD, McPherson K, Finegood DT, Moodie ML, et al. The global obesity pandemic: shaped by global drivers and local environments. The Lancet. 2011;378(9793):804-14.

6. Wetenschappelijke Raad voor het. Regeringsbeleid WR, Schilling G. Naar een voedselbeleid: Amsterdam University Press; 2014.

7. Foster M, Fell J, To H, Rees G, Bowen B. ABARES Overview of the Australian food industry, 2009-10. In: Australian Food Statistics 2009-10. Fisheries: Australian Government Department of Agriculture; 2011. Canberra.

8. Osec Swiss Business Hub Canada. The Canadian Food Retail Sector; 2011. 2011. http://www.osec.ch/sites/default/files/bbf_Canada_FoodRetail_Feb2011.pdf. [.

9. IGD. UK Grocery Retailing. http://www.igd.com/our-expertise/Retail/retail-outlook/3371/UK-GroceryRetailing. 
10. United States Department of Agiculture. Economic Research Service Food Expenditure Series. http://ers.usda.gov/data-products/food-expenditures.aspx\#26636.

11. Ocké MC, Toxopeus IB, Geurts M, Mengelers MJB, Temme EHM, Hoeymans N. Wat ligt er op ons bord?: Veilig, gezond en duurzaam eten in Nederland. 2017.

12. McCarthy EJ. Basic marketing: a managerial approach: RD Irwin; 1978.

13. Bell DR, Corsten D, Knox G. From point of purchase to path to purchase: How preshopping factors drive unplanned buying. J Mark. 2011;75(1):31-45.

14. Riesenberg D, Backholer K, Zorbas C, Sacks G, Paix A, Marshall J, et al. Price Promotions by Food Category and Product Healthiness in an Australian Supermarket Chain, 2017-2018. Am J Public Health. 2019:e1-e6.

15. Ni Mhurchu C, Vandevijvere S, Waterlander W, Thornton LE, Kelly B, Cameron AJ, et al. Monitoring the availability of healthy and unhealthy foods and non-alcoholic beverages in community and consumer retail food environments globally. obesity reviews. 2013;14:108-19.

16. Thornton LE, Cameron AJ, McNaughton SA, Waterlander WE, Sodergren M, Svastisalee C, et al. Does the availability of snack foods in supermarkets vary internationally? International Journal of Behavioral Nutrition Physical Activity. 2013;10(1):56.

17. Glanz K, Bader MD, lyer S. Retail grocery store marketing strategies and obesity: an integrative review. Am J Prev Med. 2012;42.

18. Cameron AJ, Charlton E, Ngan WW, Sacks G. A Systematic Review of the Effectiveness of Supermarket-Based Interventions Involving Product, Promotion, or Place on the Healthiness of Consumer Purchases. Current Nutrition Reports. 2016;5(3):129-38.

19. Hartmann-Boyce J, Bianchi F, Piernas C, Payne Riches S, Frie K, Nourse R, et al. Grocery store interventions to change food purchasing behaviors: a systematic review of randomized controlled trials. Am J Clin Nutr. 2018;107(6):1004-16.

20. Escaron AL, Meinen AM, Nitzke SA, Martinez-Donate AP. Peer reviewed: supermarket and grocery store-based interventions to promote healthful food choices and eating practices: a systematic review. Preventing chronic disease. 2013;10.

21. Thornton LE, Cameron AJ, McNaughton SA, Worsley A, Crawford DA. The availability of snack food displays that may trigger impulse purchases in Melbourne supermarkets. BMC Publ Health. 2012;12.

22. Horsley JA, Absalom KA, Akiens EM, Dunk RJ, Ferguson AM. The proportion of unhealthy foodstuffs children are exposed to at the checkout of convenience supermarkets. Public Health Nutr. 2014;17(11):2453-8.

23. Miller C, Bodor JN, Rose D. Measuring the food environment: a systematic technique for characterizing food stores using display counts. J Environ Publ Health. 2012;2012.

24. Ejlerskov KT, Sharp SJ, Stead M, Adamson AJ, White M, Adams J. Supermarket policies on lesshealthy food at checkouts: Natural experimental evaluation using interrupted time series analyses of purchases. PLoS Med. 2018;15(12):e1002712. 
25. Winkler LL, Christensen U, Glümer C, Bloch P, Mikkelsen BE, Wansink B, et al. Substituting sugar confectionery with fruit and healthy snacks at checkout-a win-win strategy for consumers and food stores? a study on consumer attitudes and sales effects of a healthy supermarket intervention. BMC Public Health. 2016;16(1):1184.

26. Adjoian T, Dannefer R, Willingham C, Brathwaite C, Franklin S. Healthy checkout lines: A study in urban supermarkets. J Nutr Educ Behav. 2017;49(8):615-22. e1.

27. An R. Effectiveness of subsidies in promoting healthy food purchases and consumption: a review of field experiments. Public Health Nutr. 2013;16(7):1215-28.

28. Waterlander WE, de Boer MR, Schuit AJ, Seidell JC, Steenhuis IH. Price discounts significantly enhance fruit and vegetable purchases when combined with nutrition education: a randomized controlled supermarket trial. Am J Clin Nutr. 2013;97(4):886-95.

29. Mhurchu $C N$, Blakely T, Jiang Y, Eyles HC, Rodgers A. Effects of price discounts and tailored nutrition education on supermarket purchases: a randomized controlled trial. Am J Clin Nutr. 2010;91(3):73647.

30. Ball K, McNaughton SA, Le HN, Gold L, Ni Mhurchu C, Abbott G, et al. Influence of price discounts and skill-building strategies on purchase and consumption of healthy food and beverages: outcomes of the Supermarket Healthy Eating for Life randomized controlled trial. Am J Clin Nutr. 2015;101(5):1055-64.

31. Adam A, Jensen JD. What is the effectiveness of obesity related interventions at retail grocery stores and supermarkets?-a systematic review. BMC Public Health. 2016;16(1):1247.

32. Steenhuis IH, Waterlander WE, de Mul A. Consumer food choices: the role of price and pricing strategies. Public Health Nutr. 2011;14(12):2220-6.

33. Giskes K, Avendaňo M, Brug J, Kunst A. A systematic review of studies on socioeconomic inequalities in dietary intakes associated with weight gain and overweight/obesity conducted among European adults. Obes Rev. 2010;11(6):413-29.

34. Gallo V, Mackenbach JP, Ezzati M, Menvielle G, Kunst AE, Rohrmann S, et al. Social inequalities and mortality in Europe-results from a large multi-national cohort. 2012.

35. WOZ-waardeloket. Rijksoverheid. https://www.wozwaardeloket.nl. Accessed 1 October 2015.

36. Brink E, van Rossum C, Postma-Smeets A, Stafleu A, Wolvers D, van Dooren C, et al. Development of healthy and sustainable food-based dietary guidelines for the Netherlands. Public Health Nutr. 2019:1-17.

37. Field A. Discovering Statistics Using IBM SPSS Statistics: North American Edition: SAGE; 2017.

38. Kroese FM, Marchiori DR, de Ridder DT. Nudging healthy food choices: a field experiment at the train station. J Public Health (Oxf). 2015.

39. Van Gestel LC, Kroese FM, De Ridder DTD. Nudging at the checkout counter - A longitudinal study of the effect of a food repositioning nudge on healthy food choice. Psychol Health. 2018;33(6):800-9. 
40. Cheung TTL, Gillebaart M, Kroese FM, Marchiori D, Fennis BM, De Ridder DTD. Cueing healthier alternatives for take-away: a field experiment on the effects of (disclosing) three nudges on food choices. BMC Public Health. 2019;19(1):974.

41. Foster GD, Karpyn A, Wojtanowski AC, Davis E, Weiss S, Brensinger C, et al. Placement and promotion strategies to increase sales of healthier products in supermarkets in low-income, ethnically diverse neighborhoods: a randomized controlled trial. Am J Clin Nutr. 2014;99(6):1359-68.

42. Payne $C$, Niculescu M. Can healthy checkout end-caps improve targeted fruit and vegetable purchases? Evidence from grocery and SNAP participant purchases. Food Policy. 2018.

43. Waterlander WE, Steenhuis IH, de Boer MR, Schuit AJ, Seidell JC. Introducing taxes, subsidies or both: the effects of various food pricing strategies in a web-based supermarket randomized trial. Preventive medicine. 2012;54(5):323-30.

44. Tin ST, Mhurchu CN, Bullen C. Supermarket sales data: feasibility and applicability in population food and nutrition monitoring. Nutrition reviews. 2007;65(1):20-30.

45. Appelhans BM, French SA, Tangney CC, Powell LM, Wang Y. To what extent do food purchases reflect shoppers' diet quality and nutrient intake? Int J Behav Nutr Phys Act. 2017;14(1):46.

46. Walker KZ, Woods JL, Rickard CA, Wong CK. Product variety in Australian snacks and drinks: how can the consumer make a healthy choice? Publ Health Nutr. 2008;11.

47. Foodwatch. Available online: https://www.foodwatch.org/nl/onze-campagnes/nieuwsberichten/70supermarkt-bestaat-uit-omstreden-ultra-processed-foods/ (accessed on 21 November 2018) [.

48. Vandevijvere S, Waterlander W, Molloy J, Nattrass H, Swinburn B. Towards healthier supermarkets: a national study of in-store food availability, prominence and promotions in New Zealand. European journal of clinical nutrition. 2018:1.

\section{Figures}




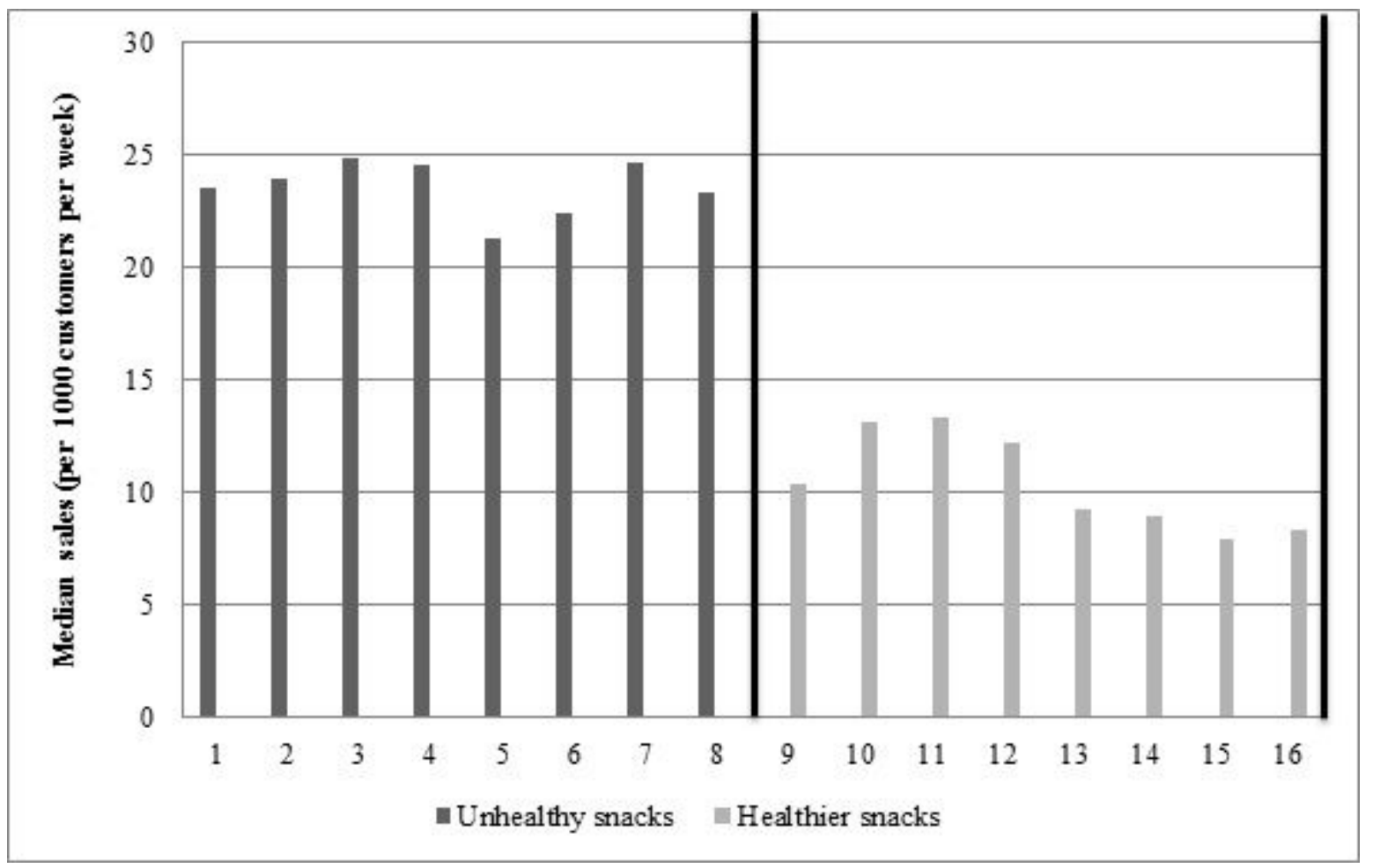

Figure 1

Median sales (items per 1000 customers per week) of unhealthy snacks and healthier snacks at checkout counters. The vertical lines mark the start and the end of the intervention period

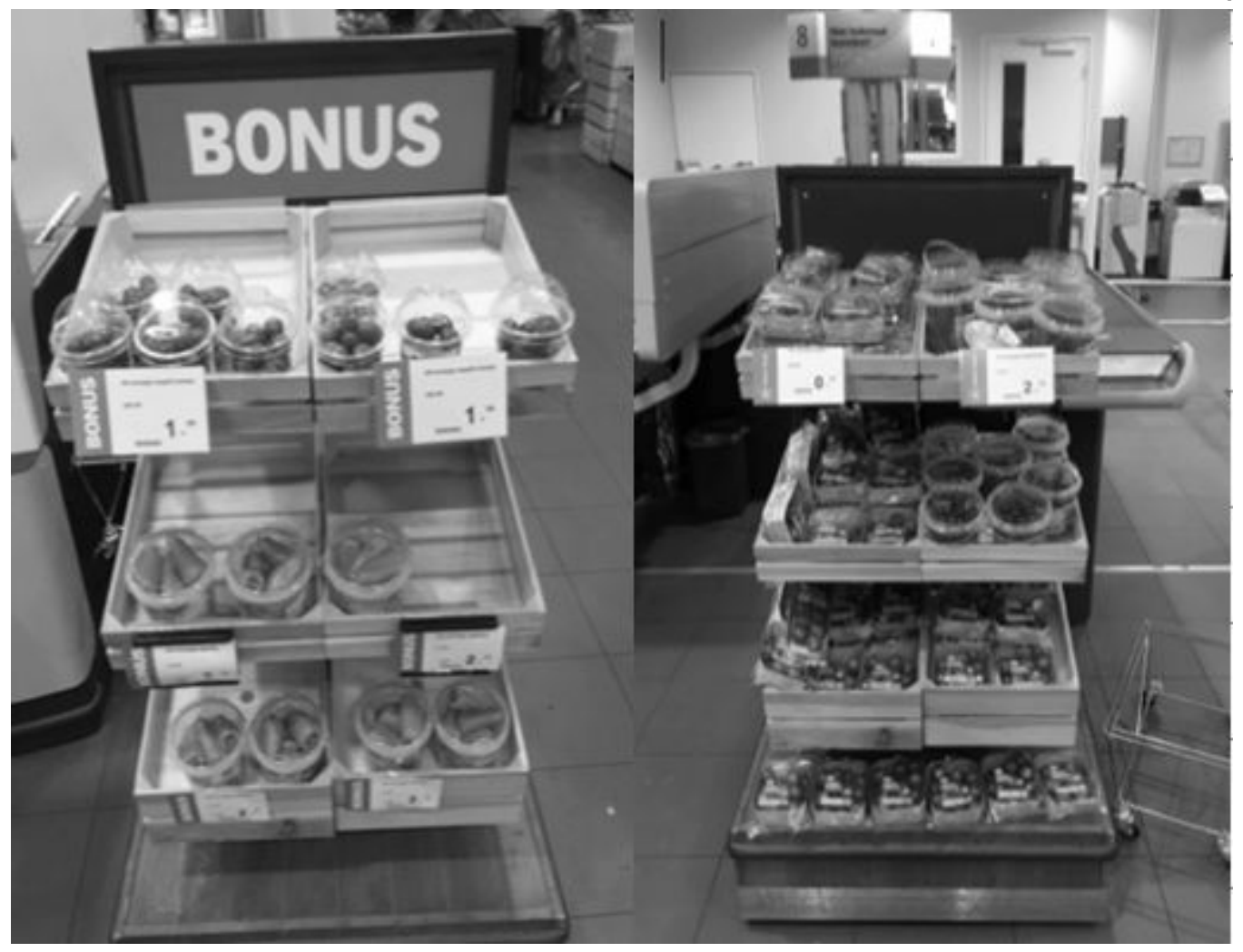

Figure 2 
Examples of a display of the placement + price intervention (left) and display of the placement ce intervention (right).

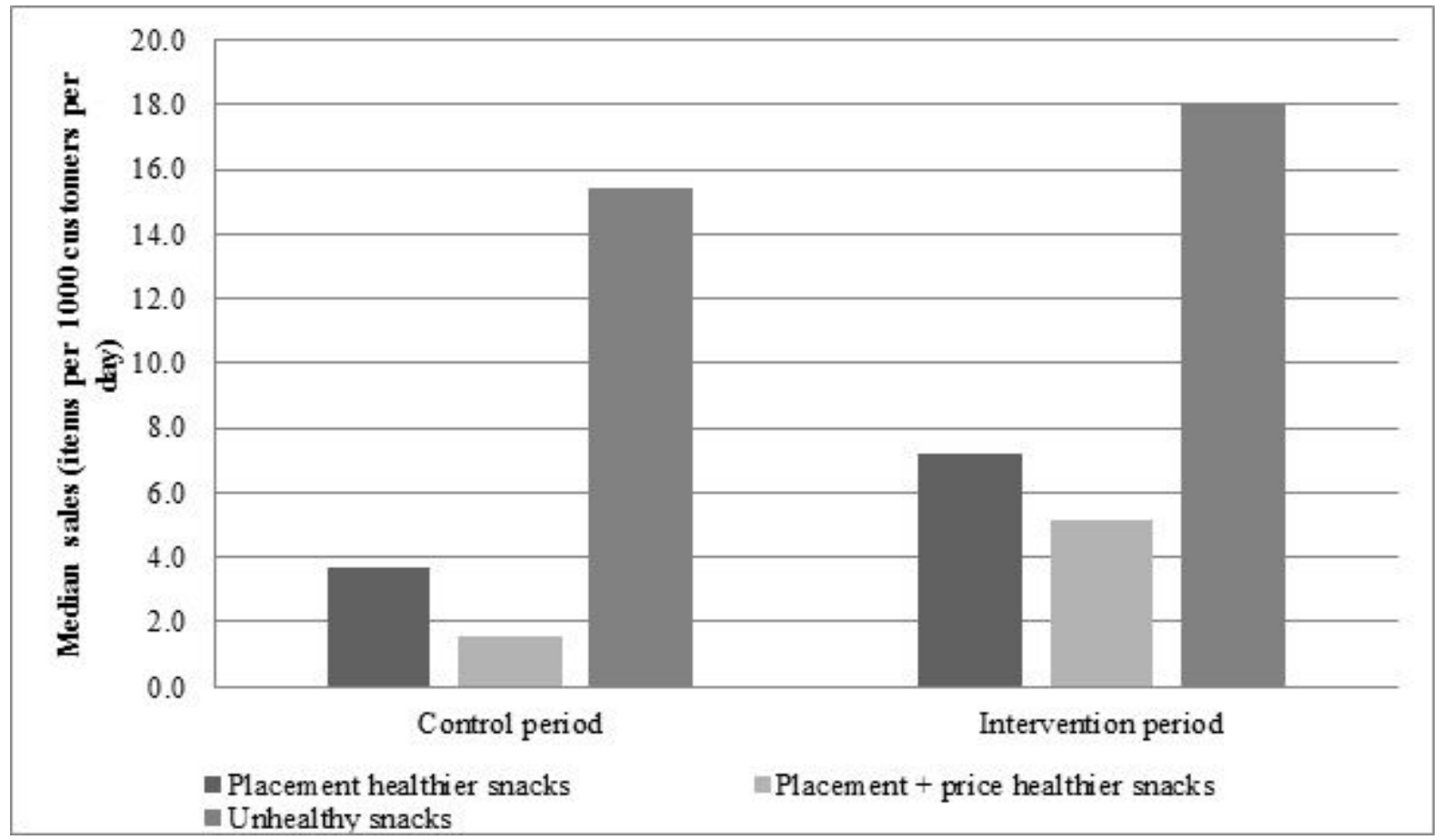

Figure 3

Median sales (per 1000 customers per day) of unhealthy snacks and healthier snacks separately for the placement intervention and the placement + price intervention in the control and intervention periods. 